\title{
Food ethics: a Wide Field in Need of Dialogue
}

\author{
Matthias Kaiser $^{1}$ • Anne Algers ${ }^{2}$
}

Published online: 13 June 2016

(C) Springer International Publishing Switzerland 2016

There are a few things which are obviously a central part of everyone's life, at all times, and all over the globe, and which are crucial for our wellbeing. Food is, like sex, such an essential ingredient of our life, an ingredient of what we expect of a good life. What is on our plates is always a result of nature and culture, to the extent that it may seem hard to find commonalities in our global diet. As academics we have asked different questions about food. For a long time these questions have been dominated by the quest to secure enough food and to improve what we have got. It is, however, noteworthy that we also always have asked the normative questions in relation to food: Is it right to eat this kind of food? Do we produce our food the right way? Is there injustice and bad power in the way we distribute the food? Are we lied to in regard to what is on our plate?

When we enter the normative realm, we enter the realm of ethics, understood in a wide and comprehensive way. As all normative questions, we need to be well informed by knowledge about how the world is, and what is at stake and for whom. We call this food ethics.

Food ethics raises issues and asks questions in relation to food all along the value chains. It also puts things into relation with each other. At the same time it disentangles complex heaps of factors and pieces of knowledge, and looks for guidance. It is issue driven, rather than interest driven. It unites scholars with farmers and fishermen, chefs with industry, consumers with lawyers, and food citizens with authorities. As a young field within academia it is important to guard against efforts to appropriate the field for narrow interests, and instead to combine the natural and social sciences in analysing and addressing the challenges. We do not necessarily call for the grand ethical theory that explains it all, but rather start with the simple things in a very complex overall picture. We want to draw attention to ethically significant facts, discuss problematic developments, point to genuine dilemmas, learn about food relevant

Matthias Kaiser

matthias.kaiser@uib.no

Anne Algers

Anne.algers@ait.gu.se

1 Centre for the Study of the Sciences and the Humanities (SVT), University of Bergen, P.O. Box 7805, 5020 Bergen, Norway

2 Department of Applied Information Technology, Gothenburg University, Gothenburg, Sweden 
contexts and history, and look for individual, professional and institutional responses to ethical challenges and issues. Thus, one of the missions of this new journal Food Ethics, is to widen the scope and the discussion on the topic, and to be inclusive in terms of who has something to contribute to the field.

There is no escaping from confronting very complex issues when it comes to managing one of the most basic needs we all have, food. As editors of this new journal we maintain that food ethics deserves special and inter-disciplinary attention by researchers, that it is not sufficiently dealt with by what is currently known as bioethics, that it is intrinsically connected with the so-called grand societal challenges of our time, that it is a globally important field which demands particular attention to complexities and uncertainties, as much as it needs to be explicit about what values are at stake and for whom, and which normative principles it touches upon.

\section{There is History}

It has always been a feature of human civilization that large parts of our diet have been somehow processed in order to improve its edibility and durability (Laudan 2001). Oftentimes raw foodstuffs are not only difficult to digest or even poisonous, but do not taste very good either. Cooking meat and vegetables, grinding corn and wheat for flour, marinating fish, or pressing crops for their oils, are age-old examples of processing techniques (-and for the benefit of any Italians: wine making as well). It was typically the privilege of the urban and richer part of the population to have ample access to these processed foodstuffs (ibid.). With the rise of greater civilizations, people started to trade with food and food ingredients. Trade was obviously dependent on means of mobility and means of storage, but as these developed, the trade also developed. Global trade in spices like salt, pepper, or nutmeg was once the equivalent of what is now the global trade in oil and gas. Coffee entered the Western world in the 17th century, first through highly controlled and monopolized trade, and then through smuggling out of the Orient and cultivating coffee plants elsewhere (Pendergrast 2010). The narrative of food was always a mirror of culture as well as a story of adventure and illustrious personalities.

It was due to the heavy industrialization of food production and processing in the 20th century that some so-called modern or developed countries managed to reduce or eliminate the risk of hunger and malnutrition. As we recall, it was problems with food security that were a non-negligible cause of the French Revolution, and that also spurred many waves of migration from Europe to America during the 19th century and the beginning of the 20th century. Food security has entered legal regulations and constitutions in several countries.

\section{There is Complexity}

New technologies for production, processing, and storing food eventually helped to reduce the problem of hunger to some significant extent. The Green Revolution of the 1960s, in spite of all its negative environmental consequences (Carson 2002), has to be credited for a globally significant move forward.

Without global trade and industrial food production and processing, even rich countries would assuredly have problems feeding their people. Therefore, there are ongoing debates 
about the sustainability of local foods and food sovereignty, which purport to change a current trend in development and consumption.

Our point of view here is that food ethics cannot be restricted to consumer choices, based on a presumed moral status of the foodstuff, or based on consequences of consumption, like e.g. health issues. Nor can it merely look at environmental and ecological aspects of production, and then include aspects of environmental ethics. Food ethics is to connect the various choices all along the complex value chain and is not only about consumers, but about citizens.

What we typically face is a highly complex and oftentimes very opaque global value chain in the supply of our foods, spanning from, for instance, a poor family shrimp farmer somewhere in SouthEast Asia, to, for instance, a wealthy consumer in a Scandinavian country. Both ends of the value chain typically know next to nothing about each other or about their socio-economic realities. And in between the two extreme ends, we find a rich variety of other actors: the suppliers of the shrimp farm, the middle-man who brings the shrimps to the local auction, the processing plant which cleans and freezes the shrimp, the certification agencies and consultants which provide the necessary quality stamps, the trading company which distributes the product via ships to various parts of the world, the retailers who integrate the product in a product line on offer in their shops.

All along this value chain choices have to be made, and many such choices involve tradeoffs between what are the recognized values of the actors. Sometimes the actors are not even aware of the implicit choices they make.

\section{There are Global Challenges}

Basically, there are five grand challenges connected to food, especially when seen with an eye to the immediate future. The list of these challenges looks like this:

- Food and population growth.

- Food and climate change.

- Food and access to natural resources.

- Food and global health issues.

- Food and the global markets.

We do not suppose we need to explain these challenges in greater detail, since the specifics and content of these grand challenges are by now widely known. Yet, we shall just briefly point to some issues under these topics, which perhaps need to be explicitly mentioned when talking about food ethics.

Food and Population Growth We detect a number of ethically problematic issues under this heading, solidarity and responsibility for current and future generations just being the most obvious ones. One issue has to do with creating hypes for certain techno-scientific developments by claiming they will provide the answer to the big challenge of feeding the world in 2050 (cf. also Godfray et al. 2010). To uphold a critical reflexivity about these claims should be integrated into our food ethics, or so we, at least, think. Furthermore, the UN, FAO, WHO, UNESCO and other organisations are profiling themselves with global development goals and some big data, all sounding very impressive, while there is seemingly good reason to submit these claims to some critical scrutiny. Hypes, hypocrisy and hollow claims would certainly constitute an ethical issue, worthy our academic analyses. 
Food and Climate Change After the FAO published its report Livestock's long shadows (2006) there is virtual unanimous agreement that our current food production, especially the production of red meat, is adding significantly to the global greenhouse gas production, and thus contributing to accelerated climate change. One must add to this the consumption pattern of particularly the rich countries (EIPRO, European Commission 2006), including food waste. One also has to consider that climate change in itself impacts food production negatively, through for instance the increase in precipitation, temperature increase, extreme weather events, salination of freshwater, and the rise of the seawater level. What we see emerging here is a debate about politics and ethics, the chances and limits of either, and the interweaving of the issues. Is it a political or an ethical claim that we should eat less red meat, and would it make a difference?

Food and Access to Natural Resources Even without the worsening effects of climate change, we may already have over-used our natural resources on land or in the sea. Ocean fish stocks are an example. Pitcher and Cheung (2013) argue that the trend to further species extinction, degradation of ecosystem food webs, and significantly reduced seafood security is continuing, alarming and urgent. But similar alarms can also be noticed from more land-based resources. We mention the decline of arable land and soil erosion. These pose in themselves some formidable ethical challenges. We want to throw in that science and technology, together with significant corporate greed, very often has been directly responsible for these developments. What have we learned form this? How would a socially responsible science and technology look like? Can we meet new challenges with old recipes? What would a postnormal science response look like (Funtowicz and Ravetz 1993)? What is not in doubt is that we indeed need to become a lot smarter.

Food and Global Health Issues Apparently improved living standards in many parts of the world have a price, and that price is obesity. In 20142 billion adults were overweight, and of these over 600 million were obese (WHO 2015a, b, c). Obesity has turned out one of the most troublesome health issues in the industrialized world. Many other diseases are related to obesity, like for instance increased incidence of diabetes II and coronary heart diseases. Food also relates to foodborne diseases and some instances of zoonoses. Nutritional advice proves, however, to be highly problematic. There is huge uncertainty about such nutritional advice, and we see emerging debates about their scientific status. Sugar consumption is now in focus and replacing earlier focus on fatty acids (The Guardian 2016). The science we produce about food related risks adds background noise but not necessarily useful information (cf. in particular Schoenfeld and Ioannidis 2013). Is there an ethics of nutritional advice?

Food and the Global Markets Contrary to the dogma of neoliberalism, markets seem never to be perfect, and they certainly do not automatically establish ethical equilibria. While the rhetoric about free trade were originally arguing that liberalization of the global food markets would be a huge benefit for the poor and underdeveloped countries, the realities have been different with the rich countries getting better control of the markets in the poor countries. The prices for rice soared in 2008. The trading of food products on the global stock markets basically equalled food products to any other products. Bio-fuel products were now in direct competition to food. The growth of inequalities between the rich and the poor world-wide as a consequence of neoliberalism pose perhaps the most significant ethical challenge (Reinert 2007). Market thinking also failed for instance in relation to GM food products which caused 
public reactions in several countries and the EU. Markets create diverse incentives, including incentives to criminal behaviour and deviance. The consensus now seems to be that markets are intrinsically unable to deal with global rights and responsibilities, and that includes, of course, ethics.

\section{There are animals}

The last decades' dramatic increase in global production and consumption of farm animal products and especially meat, mirrors increasingly intensified animal production practices (Fraser 2008; Fraser et al. 1997). With this growing intensification citizens, in particular those of Europe, have expressed increasing interest in and concern for animal welfare (Special 2007, 2016). However, farm animal welfare is addressed through different means in different cultures. The European Union constitutionally recognized through the Lisbon Treaty (2007) that animals are sentient beings and their welfare always must be taken into account in law and policy making. In the US, animal welfare is guarded by non-regulatory approaches such as voluntary standards and auditing programs interconnected to economic motivations (Mench 2008). In a global perspective, the degree of concern also varies between continents and countries (Bracke 2009) and the difference between cultures is manifest in negotiations of trade agreements. Different attitudes to animal welfare have polarized society and resulted in arson of laboratories (Friend 1990) and of animal transport vehicles for slaughter. Handling at slaughter is particularly contested since it can seriously impair animal welfare and also involves culture and religion.

Genetic selection for high productivity has generally been very successful but the flip side of the coin have been various production diseases, and the use of hormonal treatments to solve fertility problems (Oltenacu and Algers 2005). Culling of unproductive animals (Franco et al. 2014) is another side effect of industrialization of animal production. Animals are treated merely as commodities rather than living sentient beings.

It has been argued that if people ate less meat and paid a higher price for it and carefully considered the provenance of that product there could be benefits for themselves, for the farmers, for the animals, and for the planet (Appleby et al. 2014). The responsibility of the consumer concerning the ethics of intensification is under constant discussion, and since a considerable amount of food is consumed in restaurants and canteens, it is argued that the public sector has a responsibility to show leadership in the field of ethical consumption. Thus, a growing interest for the procurement of food has been found in some countries (Rimmington et al. 2006). All of this raises ethical issues in pluralistic societies where not one single set of values dominates food production. Ethical consumerism is en vogue, but its content is contentious.

The welfare of humans and animals are closely linked (FAO 2009) and we share some of the same diseases (zoonoses and lifestyle diseases). The term 'One Health' has recently been adopted, addressing health risks at the interface between animals, humans, and their environments, and is a shared initiative between FAO, OIE and WHO (OIE 2010). Animals depend on the care and nutrition that they receive from people, while the supply of food for people is dependent on healthy and productive animals. However, intensification involves high stocking densities of animals in large herds, which increases infection pressure. As a result, the use of antibiotics has increased. Furthermore, antibiotics is used as growth promoter in demanding animal environments. Excessive use significantly contributes to the development of antibiotic 
resistance in bacteria - also affecting human health. Hence, how do we achieve reasonable food production without causing side effects impairing animal and human health?

\section{Facts and Values are Intertwined}

We have argued that food ethics is characterized by great complexity and considerable uncertainty, and the disentanglement of facts and values seems impossible. When value stakes are high, as well as system uncertainties also are high, decisions are urgent, and facts and values are controversial in society, the post-normal science approach (cf. Funtowicz and Ravetz 1993, 1999) enters and argues for extended peer reviews as a crucial element of quality assurance. In post-normal science, knowledge claims are always contextualized. We would like to see more analyses what strong contextualisation can achieve in the field of food ethics. With strong contextualisation new ethical issues and dilemmas arise as a result of the growing power of society. It builds on a bottom up perspective in contrast to a top-down approach, and under certain circumstances results not in answers of right or wrong, but in a need of open and transparent models for communication, critical reflection and further development.

Our food production needs to become more sustainable. Many people agree on that, but the term "sustainability" suffers from the same flexible interpretations as the term "ethics". It is obviously tempting to look for common indicators of both, or at least treat them together in practical assessments (cf. Lam 2015). Yet, the sustainable management of a resource is so deeply value-infected (Kaiser 1997) that it seems impossible to lay down an objective basis for our assessments and preferred management schemes.

\section{Conclusion}

This new journal covers the field of food ethics, and some of its specific angles and issues have been briefly described in the above introduction. We see food ethics as a dynamic field with ever new topics and challenges arising. Thus we are in no position to provide precise definitions or good delineations of food ethics. We believe it is essentially multi- and interdisciplinary, perhaps even trans-disciplinary, in its orientation as an academic activity. Its interest unites academics, professionals, industry, politics and the public at large. We intend to maintain this wide scope in topics and approaches in order to offer something of interest for this variety of potential readers. Some specific topics will be dealt with in special issues of the journal. One such issue about animal welfare and veterinary ethics is already in the planning. We hope to combine the natural and social sciences in analysing and addressing the ethical challenges about food and food related issues. Therefore we will also welcome letters to the editors, policy briefs and discussion papers. As editors we will also occasionally contribute with opinion pieces. We hope that this journal will find its place among the regular readings of many people with an interest in food ethics.

Acknowledgments The editors want to thank Anne Murcott and Stellan Welin for very helpful discussions and comments. 


\section{References}

Appleby, M. C., Weary, D. M., and Sandøe, P. (2014). Whom should we eat? Why veal can be better for welfare than chicken. Dilemmas in Animal Welfare, 85.

Bracke, M. B. M. (2009). Animal welfare in a global perspective - a survey of foreign agricultural services and case studies on poultry, aquaculture and wildlife. ISSN 1570 - 8616. Livestock research. Wageningen UR.

Carson, R. (2002). Silent spring 1962. Houghton Mifflin Harcourt.

Environmental Impact of Products (EIPRO): Analysis of the Life Cycle Environmental Impacts Related to the Total Final Consumption of the EU 25 (2006). European commission Technical Report EUR 22284 EN.

FAO. (2009). Gateway to Farm Animal Welfare. Retrieved August 2015; from: http://www.fao.org/ag/againfo/ themes/animal-welfare/en/.

Franco, N. H., Magalhães-Sant'Ana, M. and Olsson, I. A. S. (2014). Welfare and quantity of life. Dilemmas in Animal Welfare, 46-66.

Fraser, D. 2008. Understanding animal welfare. Acta Veterinaria Scandinavica 50(Suppl 1): S1.

Fraser, D., D.M. Weary, E.A. Pajor, and B.N. Milligan. 1997. A scientific conception of animal welfare that reflects ethical concerns. Animal Welfare 6: 187-205.

Friend, T.H. 1990. Teaching animal welfare in the land grant universities. Journal of Animal Science 68: 34623467.

Funtowicz, S., and J. Ravetz. 1993. Science for the post-normal age. Futures 26(6): 568-582.

Funtowicz, S., and J. Ravetz. 1999. Post-normal science-An insight now maturing. Futures 31(7): 641-646.

Godfray, H.C.J., J.R. Beddington, I.R. Crute, L. Haddad, D. Lawrence, J.F. Muir, and C. Toulmin. 2010. Food security: the challenge of feeding 9 billion people. Science 327(5967): 812-818.

Kaiser, M. 1997. Fish-farming and the precautionary principle: Context and values in environmental science for policy. Foundations of Science 2(1997): 307-341.

Lam, M. E. (2015). The ethics and sustainability of capture fisheries and aquaculture. Journal of Agricultural and Environmental Ethics, 1-31.

Laudan, R. (2001). A Plea for culinary modernism: Why we should love new, fast, processed food, Gastronomica: The Journal of Food and Culture, charter issue, 36-44. Reprinted in Bonnie Marranca, ed., Slice of Life (Free Press, 2003).

Mench, J.A. 2008. Farm animal welfare in the USA: Farming practices, research, education, regulation, and assurance programs. Applied Animal Behaviour Science 113: 298-312.

Oltenacu, P.A., and B. Algers. 2005. Selection for increased production and the welfare of dairy cows: are new breeding goals needed? Ambio 34: 311-15.

OIE. (2010). The FAO-OIE-WHO Collaboration. A Tripartite Concept Note. April 2010. Retrieved August 2015 from: http://web.oie.int/downld/FINAL_CONCEPT_NOTE_Hanoi.pdf.

Pendergrast, M. (2010). Uncommon grounds: The history of coffee and how it transformed our world, Basic Books, 2010.

Pitcher, T.J., and W.W. Cheung. 2013. Fisheries: Hope or despair? Marine Pollution Bulletin 74(2): 506-516.

Reinert, E.S. 2007. How rich countries got rich... why poor countries stay poor. London: Constable.

Rimmington, M., J. Carlton Smith, and R. Hawkins. 2006. Corporate social responsibility and sustainable food procurement. British Food Journal 108(10): 824-837.

Schoenfeld, J.D., and J.P. Ioannidis. 2013. Is everything we eat associated with cancer? A systematic cookbook review. The American Journal of Clinical Nutrition 97(1): 127-134.

Special Eurobarometer (2007). Attitudes of EU citizens towards Animal Welfare. 270. Retrieved May 2016 from: http://ec.europa.eu/public_opinion/archives/ebs/ebs_270_en.pdf.

Special Eurobarometer (2016). Attitudes of Europeans towards Animal Welfare. 442. Retrieved May 2016 from: http://data.europa.eu/euodp/en/data/dataset/S2096_84_4_442_ENG.

The Guardian (2016). The sugar conspiracy; see: http://www.theguardian.com/society/2016/apr/07/the-sugarconspiracy-robert-lustig-john-yudkin; accessed 30.05.2016.

WHO (2015). Fact sheet number 311. http://www.who.int/mediacentre/factsheets/fs311/en/.

WHO (2015). Fact sheet number 394. http:/www.who.int/mediacentre/factsheets/fs394/en/.

WHO (2015). Press release number 240. http://www.who.int/features/qa/cancer-red-meat/en/. 